PRINT ISSN 1119-8362

Electronic ISSN 1119-8362
Full-text Available Online at https://www.ajol.info/index.php/jasem http://ww.bioline.org.br/ja
J. Appl. Sci. Environ. Manage.

Vol. 25 (9) 1617-1623 September 2021

\title{
Lipid Ratios in Adriamycin-induced Pre-eclamptic Wistar Rats Exposed to Methanolic Plant Extracts
}

\author{
*1, 2,3 ATOE, K; ${ }^{3}$ IDU, M; ${ }^{2,4}$ IKHAJIAGBE, B; ${ }^{5}$ BAKRE, AG \\ ${ }^{*}$ Department of Chemical Pathology, Edo State University Uzairue, Edo State, Nigeria () \\ ${ }^{2}$ Applied Environmental Biosciences and Public Health Research Group, Department of Microbiology, University of Benin, Benin City, \\ Nigeria \\ ${ }^{3}$ Phytomedicine and Drug Discovery Research Group, Department of Plant Biology and Biotechnology, University of Benin, Benin City, \\ Nigeria \\ ${ }^{4}$ Environmetal Biotechnology and Sustainability Research Group, Department of Plant Biology and Biotechnology, University of Benin, \\ Benin City, Nigeria \\ ${ }^{5}$ Department of Pharmacology and Therapeutics, University of Ibadan, Nigeria \\ *Corresponding Author Email: atoe.kenneth@edouniversity.edu.ng; Other Authors Email: 1617eckley.ikhajiagbe@uniben.edu; \\ ag.bakre@mail.ui.edu.ng
}

\begin{abstract}
The study accessed the lipid ratios in preeclamptic Wistar rats exposed to methanolic leaf extracts of Jatropha cacus, Alchonnea cordifolia, and Secamone afzelii. Plant samples (leaves) were washed severally with distilled water, air-dried, and crushed to powder and were filtered, then soaked in $200 \mathrm{ml}$ of methanol for 12 hours. The LD50 was determined to ascertain the safety of the plant extracts for use. Female Wistar rats, aged 3 days apart, used in the study, were acclimatized for one week. Peeclampsia was induced used the Adriamycin Model. Results showed that there was elevation of blood pressure (bp) due to preeclampsia. At $3^{\text {rd }}$ trimester, systolic bp $(177 \mathrm{mmHg})$ was higher than at postpartum $(160 \mathrm{mmHg})$. The administration of plant extracts caused a significant reduction in systolic $(127-150 \mathrm{mmHg})$ and diastolic $(86-103 \mathrm{mmHg})$ bp during the $3^{\text {rd }}$ trimester. Proteinuria was reduced to trace levels when Alchonnea cordifolia was used. Total cholesterol levels were higher in the third trimester $(71.6 \mathrm{mg} / \mathrm{dl})$ and postpartum $(74.3 \mathrm{mg} / \mathrm{dl})$, respectively. Preeclampsia was linked to similar increases in triglycerides, and low density lipoprotein cholesterol; with a reduction in high density lipoprotein cholesterol. The treatment with the various plant extracts lowered the incidence of arteriosclerotic cardiovascular events during preeclampsia. Although the extracts had a negative effect on systolic blood pressure and proteinuria during the third trimester, indicating that they were beneficial in reducing preeclampsia outcomes, there was no effect on blood pressure or proteinuria during the postpartum period.
\end{abstract}

\section{DOI:https://dx.doi.org/10.4314/jasem.v25i9.12}

Copyright: Copyright $(02021$ Atoe et al. This is an open access article distributed under the Creative Commons Attribution License (CCL), which permits unrestricted use, distribution, and reproduction in any medium, provided the original work is properly cited.

Dates: Received: 09 May 2021; Revised: 12 August 2021; Accepted: 12 September 2021

Keywords: lipid ratio, preeclampsia, dyslipidemia, lipid profile, proteinuria, blood pressure,

Pre-eclampsia is a pregnancy-related condition marked by high blood pressure and proteinuria that goes away after the baby is born. It's is a prevalent systemic pregnancy condition that is also one of the most common pregnancy disorders, as well as a major source of maternal and perinatal morbidity and mortality (Enquobahrie et al., 2004). Preeclampsia affects $7-10 \%$ of all pregnancies worldwide (Raijmakers et al., 2004). In Northern Nigeria, it accounts for $40 \%$ of maternal death, with a strong link to health-care workers' lack of understanding and a poor therapeutic interaction, however in Southern Nigeria, the prevalence rate of pre-eclampsia ranges between 5.6 and 7.6\%. (Adeosun et al., 2015). According to several studies, women with greater levels of oxidized low-density lipoprotein (LDL) and triglycerides (TG) are more likely to develop preeclampsia than normotensive pregnant women (Qiu et al., 2006; Timalsina et al., 2016). The oxidative conversion of LDL-cholesterol to oxidized LDL is a critical event in the onset and progression of atherosclerosis and hypertension (Qiu et al., 2006). Dyslipidemia in early pregnancy is associated with increased risk of preeclampsia (Enquobahrie et al., 2004). During the first trimester of pregnancy, the mother is anabolic, and the lipid acts as a source of calories for both the developing fetus and the mother. During the third trimester, the mother is catabolic, and the lipid serves as a source of calories for both the growing fetus and the mother (Lain and Catalano, 2017). A number of studies have found that abnormalities in lipid profiles may be related to the risk of preeclampsia. Triglycerides, LDL and total cholesterol in the preeclamptic women are greater than regular pregnancies, however in preeclamptic women high density level of lipoprotein (HDL) is lower compared to normal pregnancy (De et al., 2006; Baker et al., 2009; Thathagari and Kumar, 2018). Although 
there is emerging evidence that excessive levels of oxidized low density lipoproteins and triglycerides enhance the risk of preeclampsia (Qiu et al., 2006), the role of lipid peroxidation in the pathophysiology of preeclampsia remains unclear. The aim of the study is to assess the changes in lipid profile and lipid ratio that occurs during preeclampsia, as well as the impact of plant extracts on the management.

\section{MATERIALS AND METHODS}

Collection and preparation of plant samples: Plant samples (leaves) were collected from first-generation farms located at Iguosula, Uhunmwonde Local Government area, Edo State. They were identified and verified at the Phytomedicine Unit, Department of Plant Biology and Biotechnology, University of Benin, Benin City. The plant samples were cleansed with distilled water several times, then air-dried for two weeks before being crushed into powder with a
Panasonic $₫$ medium kitchen blender, model MXGX1021WTZ. The extracts were filtered using Whatman Filter Paper No 42 after soaking 100g of each powder sample in $200 \mathrm{ml}$ of methanol for 12 hours $(125 \mathrm{~mm})$.

Study design: The study employed age-matched (three days) female Wistar rats weighing 220 to $256 \mathrm{~g}$ (mean, $237 \mathrm{~g}$ ). The animals were provided unrestricted access to a regular diet with the following composition; $0.35 \mathrm{~g} \mathrm{NaCl}, 20 \mathrm{~g}$ protein, and $1.17 \mathrm{~g}$ arginine per $100 \mathrm{~g}$ food. They were also provided tap water ( $\mathrm{pH}$ range 6.8-7.2) ad libitum.

In this experiment, the wister rats were randomly divided into fifteen (15) groups, each with ten (10) rats. The positive control was Group 1, whereas the negative controls were Groups 2, 3, and 4. The rest of the groups are listed below (Table 1).

Table 1: Designation of experimental groups

\begin{tabular}{ll}
\hline Group & Description \\
\cline { 2 - 2 } Group 1 & Control \\
Group 2 & Administered with Ext-JC (No induced Preeclampsia) \\
Group 3 & Administered with Ext-AC (No induced Preeclampsia) \\
Group 4 & Administered with Ext-SA (No induced Preeclampsia) \\
Group 5 & Induced Preeclampsia, no treatment provided \\
Group 6 & Induced Preeclampsia $+100 \mathrm{mg} / \mathrm{kg}$ Standard drug \\
Group 7 & Induced Preeclampsia $+50 \mathrm{mg} / \mathrm{kg}$ Ext-JC \\
Group 8 & Induced Preeclampsia $+100 \mathrm{mg} / \mathrm{kg}$ Ext-JC \\
Group 9 & Induced Preeclampsia $+200 \mathrm{mg} / \mathrm{kg}$ Ext-JC \\
Group 10 & Induced Preeclampsia $+50 \mathrm{mg} / \mathrm{kg}$ Ext-AC \\
Group 11 & Induced Preeclampsia $+100 \mathrm{mg} / \mathrm{kg}$ Ext-AC \\
Group 12 & Induced Preeclampsia $+200 \mathrm{mg} / \mathrm{kg}$ Ext-AC \\
Group 13 & Induced Preeclampsia $+50 \mathrm{mg} / \mathrm{kg}$ Ext-SA \\
Group 14 & Induced Preeclampsia $+100 \mathrm{mg} / \mathrm{kg}$ Ext-SA \\
Group 15 & Induced Preeclampsia $+200 \mathrm{mg} / \mathrm{kg}$ Ext-SA \\
\hline
\end{tabular}

Ext-JC, Metholic leaf extract of Jatropha cacus; Ext-AC, Metholic leaf extract of Alchonnea cordifolia; Ext-SA, Metholic leaf extract of Secamone afzelii. Standard drug was methyl DOPA (Aldomet $\left.{ }^{\circledR}\right)$

Preeclampsia induction: The Adriamycin Model adopted by Podjarny et al (1992) was used. Under light ether anesthesia, rats were given Adriamycin (Adriablastina, Abic) at a dose of $3.5 \mathrm{mg} / \mathrm{kg} \mathrm{IV}$ into a superficial femoral vein. The rats were mated with a fertile male for four days after two weeks.

Experimental animal care and management: The animals were cared for and used in compliance with international guidelines for laboratory animal care and use (NRC, 2011).

Experimental animal sacrifice: Twenty four (24) hours after administration of the last dose of the standard drug and various treatment extracts to the respective groups, the animals were anaesthetized with chloroform and humanely sacrificed (Rowell, 1977).
Processing blood for serum: The approach described by Dave and Lewis (1986) for processing blood for serum was employed. Blood samples were taken through heart puncture and placed in a simple vial. After allowing the sample to clot, it was centrifuged for 15 minutes at 3000rpm to get clear slightly yellow supernatant serum.

Determination of Lipid profile levels: The lipid analysis was carried out using a spectrophotometer, and the kits were provided by Randox Laboratory Limited. The procedure employed was the standard operational assay. The blood lipid indices were calculated using the equations below; 
Friedewald equation for LDL Chol. $=\mathrm{TC}-\mathrm{TG} / 5-$ HDL Chol. (mg/dl)

Atherogenic index plasma, AIP $=\log$ (TG/HDLChol.)

Atherogenic cooefficient, $\mathrm{AC}=$ (Non HDL Chol/ HDL Chol.)

Non-HDL cholesterol, NHDL = VLDL + LDL Chol. Very low density lipotrotein, $\mathrm{VLDL}=$ Triglycerides $/ 5$ Castelli Risk Index I, CRI I = TC/ HDL Chol. Castelli Risk Index II, CRI II = LDLC/HDLC

Statistical analysis: Data collected were analyzed using SPSS version 20. Results were presented in Tables and Quantitative variables were expressed as mean \pm SD.

Ethical issues: The Research and Ethics Committee of the Faculty of Life Sciences, University of Benin, Benin City, granted ethical permission with reference LS19017, dated March 7, 2019.

\section{RESULTS AND DISCUSSION}

Figure 1 shows the $\mathrm{LD}_{50}$ of the extract administered to the Wistar rats. There was no mortality recorded upon administration of the various plant extracts, thus indicating safety of use. Preeclampsia caused an increase in blood pressure (BP) (Table 2). The systolic blood pressure $(177 \mathrm{mmHg})$ was greater in the third trimester than it was postpartum $(160 \mathrm{mmHg})$. During the third trimester, plant extracts generated a significant drop in systolic $(127-150 \mathrm{mmHg})$ and diastolic $(86-103 \mathrm{mmHg})$ blood pressure. The lowest bp $(118 / 86 \mathrm{mmHg})$ was obtained when preeclamptic animals were administered $100 \mathrm{mg} / \mathrm{kg}$ of Jatropha cacus. Generally, systolic bp during postpartum were lower than at $3^{\text {rd }}$ trimester. Table 3 shows the effects of plant extract treatment on the incidence of proteinuria in rat models.

As presented, the control animals as well as those administered the plant extracts did not show signs of proteinuria. However, incidence of preeclampsia presented positive proteinuria cases for the test animals. At $3^{\text {rd }}$ trimester proteinuria level was 3 times that at postpartum. Administration of plant extracts reduced proteinuria during $3^{\text {rd }}$ trimester generally by one-thirds. At post-partum however, treatment of test animals with plant extracts reduced proteinuria by two-thirds with the use of $100 \mathrm{mg} / \mathrm{kg}$ Jatropha cacus and Secamone afzelii respectively. The use of Alchonnea cordifolia resulted in reduction of proteinuria to trace levels.

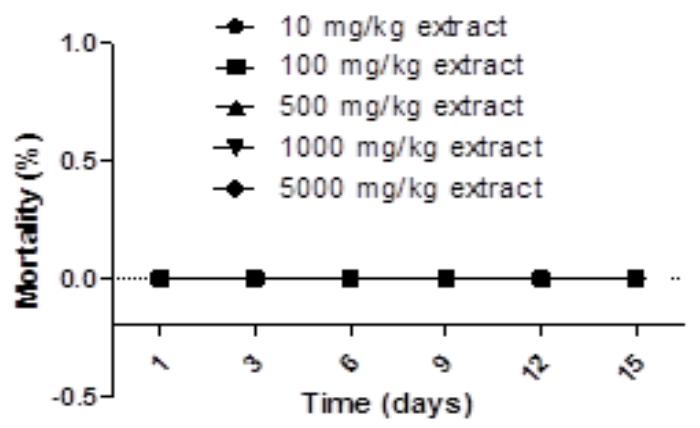

Fig 1: Presentation of $\mathrm{LD}_{50}$

Table 2: Presentation of blood pressure results after administration of selected plant extracts to preeclamptic Wistar rats

\begin{tabular}{|c|c|c|c|c|c|c|}
\hline \multirow[t]{2}{*}{ Treatments } & (n) & Systolic & Diastolic & (n) & Systolic & Diastolic \\
\hline & \multicolumn{3}{|c|}{ 3rd trimester } & \multicolumn{3}{|c|}{ Post-partum } \\
\hline Control & 14 & 124 & 98 & 8 & 121 & 96 \\
\hline Only Ext-A (No induced PreEc) & 15 & 119 & 85 & 12 & 110 & $85^{*}$ \\
\hline Only Ext-B (No induced PreEc) & 19 & 132 & 101 & 13 & 122 & 94 \\
\hline Only Ext-C (No induced PreEc) & 19 & 131 & 95 & 12 & 123 & 91 \\
\hline Induced PreEc, no treatment & 26 & $177 *$ & $121 *$ & 12 & $160 *$ & $125^{*}$ \\
\hline Induced PreEc $+100 \mathrm{mg} / \mathrm{kg} \mathrm{StdD}$ & 36 & 141 & 103 & 10 & 135 & 104 \\
\hline Induced PreEc $+50 \mathrm{mg} / \mathrm{kg}$ Ext-JC & 16 & 143 & 99 & 7 & 117 & 93 \\
\hline Induced PreEc + 100 mg/kg Ext-JC & 12 & 118 & 86 & 4 & 129 & 101 \\
\hline Induced PreEc + 200 mg/kg Ext-JC & 12 & 145 & 100 & 3 & 119 & 99 \\
\hline Induced PreEc $+50 \mathrm{mg} / \mathrm{kg}$ Ext-AC & 14 & 143 & 97 & 4 & 113 & 90 \\
\hline Induced PreEc $+100 \mathrm{mg} / \mathrm{kg}$ Ext-AC & 10 & 136 & 96 & 5 & 113 & 87 \\
\hline Induced PreEc + $200 \mathrm{mg} / \mathrm{kg}$ Ext-AC & 19 & 127 & 87 & 10 & 127 & 94 \\
\hline Induced PreEc + $50 \mathrm{mg} / \mathrm{kg}$ Ext-SA & 11 & 140 & 98 & 6 & 136 & 102 \\
\hline Induced PreEc $+100 \mathrm{mg} / \mathrm{kg}$ Ext-SA & 16 & 141 & 101 & 6 & 116 & 86 \\
\hline Induced PreEc + $200 \mathrm{mg} / \mathrm{kg}$ Ext-SA & 13 & $150 *$ & 92 & 8 & 121 & 106 \\
\hline $\operatorname{LSD}(0.05)$ & & 22 & 14 & & 16 & 11 \\
\hline F-test & & 5.913 & 7.795 & & 4.332 & 4.241 \\
\hline $\mathrm{p}$-value & & $<0.001$ & $<0.001$ & & $<0.001$ & $<0.001$ \\
\hline
\end{tabular}

* Means are significantly different from the Control $(\mathrm{p}<0.05)$. Values presented are to the nearest integer. Ext-JC, Metholic leaf extract of Jatropha cacus; Ext-AC, Metholic leaf extract of Alchonnea cordifolia; Ext-SA, Metholic leaf extract of Secamone afzelii. Standard drug was methyl DOPA (Aldomet $\left.{ }^{\circledR}\right)$ 
Table 3: Effects of administration of plant extracts on incidence of proteinuria in the preeclamptic Wistar rats

\begin{tabular}{llll}
\hline Group & Baseline & At Third trimester & At post-partum \\
\hline Control & Negative & Negative & Negative \\
Only Ext-A (No induced PreEc) & Negative & Negative & Negative \\
Only Ext-B (No induced PreEc) & Negative & Negative & Negative \\
Only Ext-C (No induced PreEc) & Negative & Negative & Negative \\
Induced PreEc, no treatment provided & +++ & +++ & + \\
Induced PreEc $+100 \mathrm{mg} / \mathrm{kg}$ StdD & NA & + & Trace \\
Induced PreEc $+50 \mathrm{mg} / \mathrm{kg}$ Ext-JC & NA & + & Trace \\
Induced PreEc $+100 \mathrm{mg} / \mathrm{kg}$ Ext-JC & NA & ++ & + \\
Induced PreEc $+200 \mathrm{mg} / \mathrm{kg}$ Ext-JC & NA & ++ & Trace \\
Induced PreEc $+50 \mathrm{mg} / \mathrm{kg}$ Ext-AC & NA & ++ & Trace \\
Induced PreEc $+100 \mathrm{mg} / \mathrm{kg}$ Ext-AC & NA & ++ & Trace \\
Induced PreEc $+200 \mathrm{mg} / \mathrm{kg}$ Ext-AC & NA & ++ & Trace \\
Induced PreEc $+50 \mathrm{mg} / \mathrm{kg}$ Ext-SA & NA & ++ & Trace \\
Induced PreEc $+100 \mathrm{mg} / \mathrm{kg}$ Ext-SA & NA & ++ & + \\
Induced PreEc $+200 \mathrm{mg} / \mathrm{kg}$ Ext-SA & NA & ++ & Trace \\
\hline \multicolumn{2}{c}{ Present + (The number of “+ indicates level of severity $) ;$ NA not applicable }
\end{tabular}

Table 4 shows the dyslipidemia observed in induced test animals after exposure to plant extracts. There was elevated total cholesterol (TC) at both $3^{\text {rd }}$ trimester (71.6 $\mathrm{mg} / \mathrm{dl})$ and postpartum $(74.3 \mathrm{mg} / \mathrm{dl})$ respectively. Similar increases in Triglycerides (TG), High density lipoprotein cholesterol (HDL) and low density lipoprotein cholesterol (LDL) were reported due to preeclampsia. It was observed that there were significant differences between the TC, TG, HDL and LDL at the 3rd trimester. At post-partum, there were no significant differences between the TC and LDL among the groups treated with the plant extracts. While, there were significant differences between TG and HDL. There was significant decrease in lipids parameters in the Induced PreEc $+100 \mathrm{mg} / \mathrm{kg}$ Ext-C, Induced PreEc $+50 \mathrm{mg} / \mathrm{kg}$ Ext-C and Induced PreEc $+50 \mathrm{mg} / \mathrm{kg}$ Ext-B group compared to the control group in the 3rd trimester, but significant increase across the other groups.

Table 4: Lipid profiles in induced test animals after exposure to plant extracts

\begin{tabular}{|c|c|c|c|c|c|c|c|c|}
\hline \multirow[t]{2}{*}{ Treatments } & $\mathrm{TC}$ & $\mathrm{TG}$ & $\mathrm{HDL}$ & LDL & $\mathrm{TC}$ & TG & HDL & LDL \\
\hline & \multicolumn{4}{|c|}{ 3rd Trimester } & \multicolumn{4}{|c|}{ Post-partum } \\
\hline Control & 43.2 & 51.4 & 17.4 & 32.9 & 39.9 & 47.1 & 13.5 & 31.2 \\
\hline Only Ext-A (No induced PreEc) & 42.5 & 46.6 & 18.3 & 33.2 & 43.2 & 38.2 & 15.6 & 33.7 \\
\hline Only Ext-B (No induced PreEc) & 51.3 & 41.5 & 27.7 & 41.2 & 46.3 & 40.3 & 15.2 & 36.4 \\
\hline Only Ext-C (No induced PreEc) & 46.8 & 61.2 & 32.4 & 33.8 & 40.5 & 38.4 & 37.3 & 33.2 \\
\hline Induced PreEc, no treatment provided & 71.6 & 66.2 & 16.4 & 57.2 & 74.3 & 59.7 & 11.3 & 63.9 \\
\hline Induced PreEc $+100 \mathrm{mg} / \mathrm{kg}$ StdD & 59.2 & 52.1 & 15.7 & 46.8 & 47.3 & 43.4 & 14.7 & 38.1 \\
\hline Induced PreEc $+50 \mathrm{mg} / \mathrm{kg}$ Ext-JC & 69.7 & 59.6 & 19.3 & 56.4 & 36.7 & 33.1 & 13.8 & 39.2 \\
\hline Induced PreEc +100 mg/kg Ext-JC & 50.4 & 36.7 & 13.3 & 44.3 & 55.3 & 42.4 & 16.1 & 46.8 \\
\hline Induced PreEc $+200 \mathrm{mg} / \mathrm{kg}$ Ext-JC & 48.2 & 39.2 & 18.0 & 41.3 & 44.5 & 40.3 & 37.6 & 36.4 \\
\hline Induced PreEc $+50 \mathrm{mg} / \mathrm{kg}$ Ext-AC & 33.7 & 31.2 & 12.4 & 27.5 & 49.7 & 44.3 & 16.2 & 39.4 \\
\hline Induced PreEc $+100 \mathrm{mg} / \mathrm{kg}$ Ext-AC & 46.1 & 41.3 & 34.8 & 37.2 & 34.4 & 30.3 & 15.4 & 29.1 \\
\hline Induced PreEc $+200 \mathrm{mg} / \mathrm{kg}$ Ext-AC & 43.3 & 38.2 & 34.9 & 36.5 & 57.3 & 47.2 & 14.3 & 47.9 \\
\hline Induced PreEc $+50 \mathrm{mg} / \mathrm{kg}$ Ext-SA & 38.2 & 30.1 & 12.3 & 33.2 & 56.8 & 38.7 & 15.3 & 45.2 \\
\hline Induced PreEc + $100 \mathrm{mg} / \mathrm{kg}$ Ext-SA & 39.4 & 33.7 & 9.7 & 32.6 & 53.4 & 47.7 & 15.6 & 42.5 \\
\hline Induced PreEc + $200 \mathrm{mg} / \mathrm{kg}$ Ext-SA & 55.6 & 44.0 & 18.7 & 46.8 & 40.4 & 39.4 & 32.6 & 33.2 \\
\hline $\operatorname{LSD}(0.05)$ & 12.1 & 7.2 & 11.2 & 18.4 & 14.13 & 4.03 & 3.91 & 6.31 \\
\hline p-value & 0.121 & 0.138 & 0.329 & 0.422 & $<0.001$ & 0.005 & 0.568 & $<0.001$ \\
\hline
\end{tabular}

Castelli risk ratio (CRI, 1) was 2.48 in the control, but was elevated (4.37) in the preeclampstic rats (Table 5). However, CRI (I) in the $3^{\text {rd }}$ trimester was during postpartum (6.58) in the preeclamptic rats. Reductions in CRI as well as other lipid ratios was reported in both $3^{\text {rd }}$ trimester and postpartum when rats were administered different doses of the plant extracts. The risk of arteriosclerotic cardiovascular events during preeclampsia was reduced upon the administration of the plant extracts (Table 5). Figure 2(a) shows the canonical correspondence biplot in the 3rd trimester. It was observed that HDL positively influenced Ext-B (med) and Ext-B (high) owing to its close relationship, while proteinuria influenced Ext-A (high) on Axis 2. 
Table 5: Presentation of lipid ratios in induced test animals after exposure to plant extracts

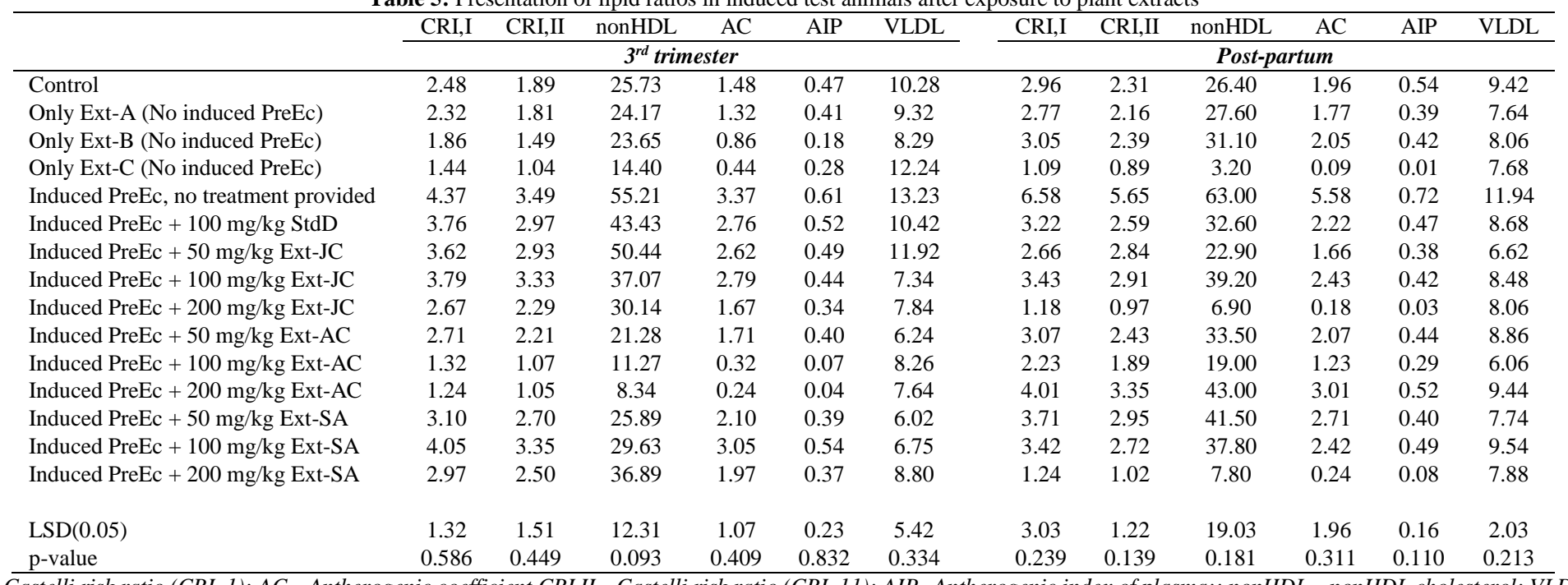

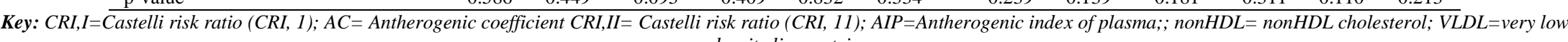
density lipoprotein

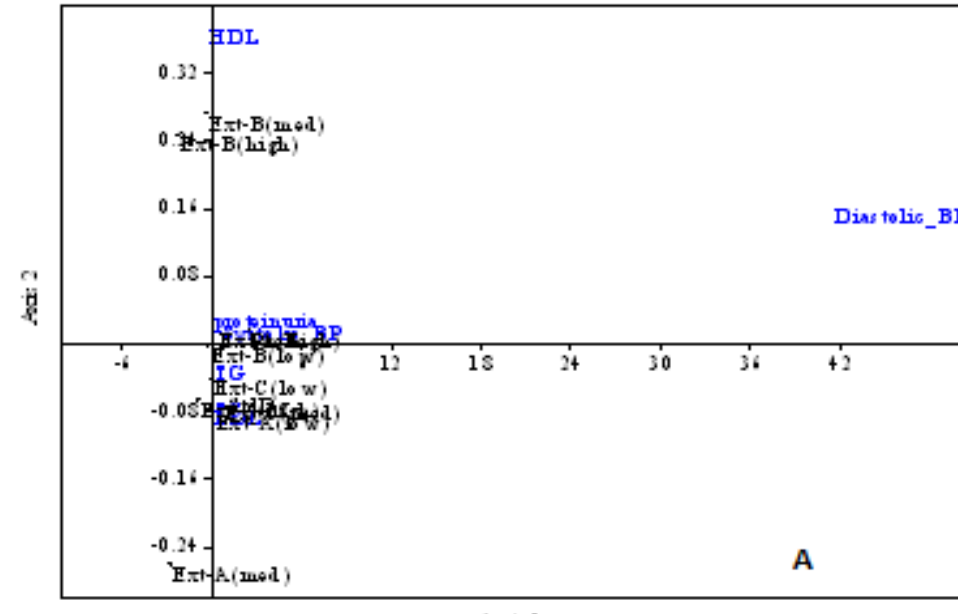

Axis

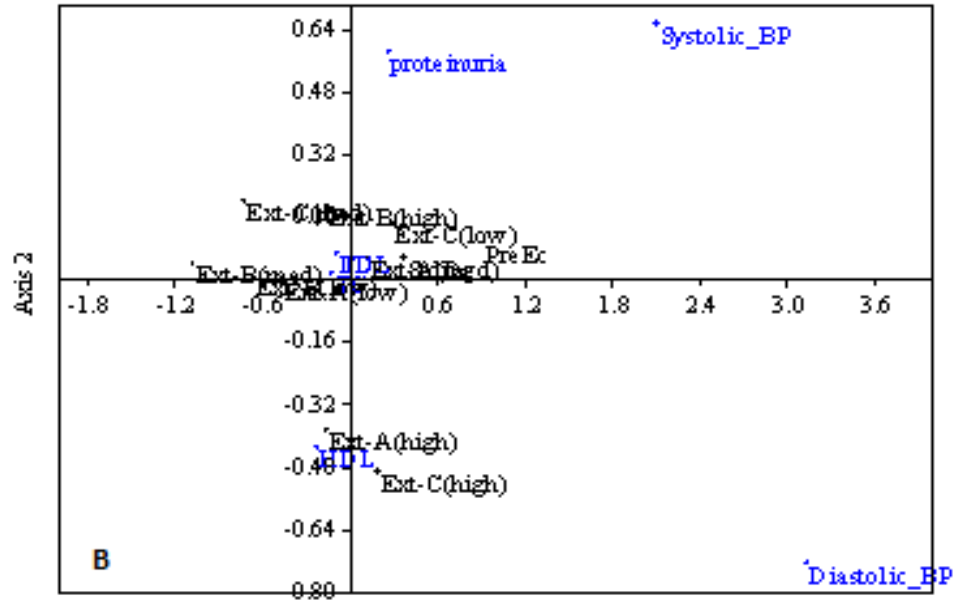

Axis 1

Fig 2: Canonical correspondence ballot showing association between measured parameters and the plant extracts during (a) $3^{\text {rd }}$ trimester and (b) postpartum. Ext-A, Metholic leaf extract of Jatropha cacus; Ext-B, Metholic leaf extract of Alchonnea cordifolia; Ext-C, Metholic leaf extract of Secamone afzelii. Standard drug was methyl DOPA (Aldomet ${ }^{\circledR}$ ) 
However, TG, HDL negatively influenced other Although systolic bp as well as proteinuria were negatively influenced during $3^{\text {rd }}$ trimester, implying the impact of treatments on improving the outcome of preeclampsia (Figure 2a), blood pressure and proteinuria were not influenced by the intervention of plant extracts during postpartum (Figure $2 b$ ).

However, the outcome of this study is in contrast to Tanir et al. (2005), who found a rise in blood pressure in preeclampsia rats after giving them plant extract. Many studies have been conducted to investigate the relationship between preeclampsia complications and the level of proteinuria. Several studies have found that moderate or severe proteinuria increases the likelihood of poor maternal and fetal outcomes (Ferrazzani et al., 1990; Chan et al., 2005; Thangaratinam et al., 2009). Other research has found that the severity of proteinuria in women with preeclampsia is a poor predictor of either maternal or fetal problems (Airoldi et al., 2000; Thangaratinam et al., 2009). Therefore, the management of proteuria with herbal remedies is imperative. There was significant reduction in proteinuria upon administration of various plant extracts. In a study by Jaiswal et al. (2009) to assess the effect of Moringa oleifera leaves aqueous extract therapy on urine protein, significant reduction was found in urine protein levels from +2 to trace. Methanolic extracts of Jatropha cacus, Alchonnea cordifolia, and Secamone afzelii were found to be a promising source of preeclampsia management in this study. The normotensive pregnant Wistar rats was the control group, whereas, preclampsia pregnant Wistar rats were test group. The study showed positive relationship between dyslipidemia and preeclampsia. This is in keeping with other studies (Gractacose et al., 2003; Winkler et al., 2003; Enquobahrie et al., 2004; Toescu et al., 2004, Ray et al., 2006). In normal pregnancy, studies have shown that TC, TG, HDL, and LDL levels are significantly increased. However, in preeclampsia, instead of an increase in HDL, which is cardioprotective, there is a decrease in HDL (see Table 4), which makes the preeclamptic subject more susceptible to atherogenicity and the risk of cardiovascular heart disease. In a study by Maruthappan and Shree (2010), aqueous extract of Phyllanthus reticulates $(250 \mathrm{mg}$ and $500 \mathrm{mg} / \mathrm{kg}$ ) caused a significant reduction triglyceride, VLDLcholesterol, total cholesterol (TC), and LDLcholesterol levels, while increasing HDL-cholesterol in atherogenic diet-induced hypercholesterolemic rats (45 days). Ighodaro and Omole (2012) also reported reduction in lipid profiles using Piliostigma thonningii leaf extract in wistar rats. Similar to the present study, the reduction in the aforesaid parameters were reported. The lipid ratios, which include the artherogenic coefficient (AC), the artherogenic index of plasma (AIP), and Castelli risk ratios (CRI), were found to be significantly high (see Table 5) in this study. The higher the lipid ratio, the greater the risk of atherosclerotic heart disease; however, when the plant extracts were administered, the lipid ratios significantly decreased.

Conclusion: Methanolic leaf extracts of Jatropha cacus, Alchonnea cordifolia, and Secamone afzelii were found to have a significant impact on preeclampsia treatment by lowering blood pressure, proteinuria, lipid profile parameters, and lipid ratios, in line with the findings of this study.

Acknowledgement: The researchers are grateful to Mr. Francis Aibuedefe Igiebor, Research Assiatnt, for helping with initial typesetting of the manuscript.

\section{REFERENCES}

Adeosun, OG; Charles-Davies, MA; Ogundahunsi, OA; Ogunlewe, J (2015). Maternal and neonatal outcome of pre-eclampsia in African black women; South west Nigeria. Greener Journal of Medical Sciences 5(4), 067-076.

Anorlu, RI; Iwuala, NC; Odum, CU (2005). Risk factors for pre-eclampsia in Lagos; Nigeria. Aust $N$ Z J Obstet Gynaecol. 45(4):278-82.

Baker, AM; Klein, RL; Moss, KL; Haeri, S; Boggess, K (2009) Maternal serum dyslipidemia occurs early in pregnancy in women with mild but not severe preeclampsia. Am. J. Obstet. Gynecol. 201(3):291-294.

De, J; Mukhopadhyay, AK; Saha, PK. (2006) Study of serum lipid profiles in Pregnancy Induced Hypertension. Indian Journal of Clinical Biochemistry 21(2):165-168.

Enquobahrie, DA; Williams, MA; Butler, CL; Frderick, IO; Miller, RS; Luthy, DA. (2004). Maternal plasma lipid concentration in early pregnancy and risk of preeclampsia. Am. J. Hypertens. 17(7):574-581.

Faulkner, WR (1982). Selected method for the small clinical chemistry laboratory. "Magnesium in Biological Fluids” AACC Washington; D.C. p277.

Getiye, Y; Tolessa, T; Engidawork, E. (2016). Antihypertensive activity of $80 \%$ methanol seed extract of Calpurnia aurea (Ait.) Benth. subsp. aurea (Fabaceae) is mediated through calcium 
Lipid Ratios in Adriamycin-induced Pre-eclamptic Wistar Rats.....

antagonism induced vasodilation. Ethnopharmacol. 189:99-106.

Gractacose, E; Casals, E; Gomez, O; Llurba, E; Mercader, I; Carach, V. (2003). Increased susceptibility to low density lipoprotein oxidation in women with a history of pre-clampsia. $B r . J$. Obstet. Gynaecol. 110(4):400-404.

Ighodaro, MO; J. O. Omole, JO (2012). Effects of Nigerian Piliostigma thonningii species leaf extract on lipid profile in wistar rats. Inter. Scholarly Res. Notices, Article ID 387942

Jaiswal, D; Kumar Rai, P; Kumar, A; Mehta, S; Watal, G. (2009). Effect of Moringa oleifera Lam. leaves aqueous extract therapy on hyperglycemic rats. $J$. Ethnopharmacol. 123(3): 392-396.

Kaplan, LA; Pesce, AJ (1996). Clinical Chemistry Theory; Analysis and Correlation; 3rd Edition; C.V. Mosby, St. Louis.

Lain, KY; Catalano, PM. (2017) Metabolic Changes in Pregnancy. Clinical Obstetrics and Gynecology 50(4):938-948.

Maruthappan, V; Shree, KS. (2010). Effects of Phyllanthus reticulatus on lipid profile and oxidative stress in hypercholesterolemic albino rats. Indian Journal of Pharmacology, 42(6), 388391.

Mushtaq, MN; Akhtar, MS; Alamgeer; Ahmad, T; Khan, HU; Maheen, S; Ahsan, H; Naz, H; Asif, H; Younis, W; Tabassum, N. (2016). Evaluation of antihypertensive activity of Sonchus asper L. in rats. Acta Pol. Pharm. 73(2): 425 - 431.

Natelson, S (1971). Techniques of Clinical Chemistry. 3rd Ed. Thomas C.C; Springfield; IL. p190.

National Research Council (NRC) (2011). Guide for the care and use of laboratory animals (8th Edition). The National Academic Press; Washington; D.C; 246p.

Podjarny, E; Bernheim, J; Rathaus, M; Pomeranz, A; Tovbin, D; Shapira, J; Bernheim, J (1992). driamycin nephropathy: a model to study effects of pregnancy on renal disease in rats. Am. J. Physiol. 263(4 Pt 2): 711 - 715.

Podjarny, E; Losonczy, G; Baylis, C. (2004). Animal models of preeclampsia. Seminars in Nephrology 24(6); 596-606.
Qiu, C; Phung, TTT; Vadachkoria, S; Muy-Rivera, M; Sanchez, SE; Williams, MA. (2006). Oxidized Low-Density Lipoprotein (Oxidized LDL) and the Risk of Preeclampsia. Physiol Res. 55:491-500.

Raijmakers, MT; Dechend, R; Poston, L. (2004). Oxidative stress and preeclampsia: rationale for antioxidant clinical trials. Hypertension 44(4):374-380.

Ray, JG; Diamond, P; Singh, G; Bell, CM. (2006). Brief overview of maternal triglycerides as a risk factor for pre-eclampsia. Br. J. Obstet. Gynaecol. 113(4):379-386.

Rundle, C (2011). A Beginners Guide to Ion-Selective Electrode Measurements. Nico2000 Ltd; London; UK. Available online: http://www.nico2000.net/Book/Beginners_Guide. pdf

Tanir, HM; Sener, T; Inal, M; Akyuz, F; Uzuner, K; Sivri, E. (2005). Effect of quercetine and glutathione on the level of superoxide dismutase; catalase; malonyldialdehyde; blood pressure and neonatal outcome in a rat model of pre-eclampsia induced by NG-nitro-1-arginine-methyl ester. Eur. J. Obstet. Gynecol. Reprod. Biol. 118:190-195.

Thathagari, V; Kumar, VCM. (2018). Evaluation of serum lipids in preeclampsia: a comparative study. Int J Reprod Contracept Obstet Gynecol. 7:13721375.

Tietz, NW (1987). Fundamentals of Clinical Chemistry; 3rd Edition; W.B. Saunders. p720.

Timalsina, S; Gyawali, P; Bhattarai, A. (2016) Comparison of lipid profile parameters and oxidized low-density lipoprotein between normal and preeclamptic pregnancies in a tertiary care hospital in Nepal. Int. J. Womens Health 8: 627631.

Toescu, V; Nuttall, SL; Martin, U; Nightingale, P; Kendall, MJ; Brydon, P (2004). Changes in plasma lipids and markers of oxidative stress in normal pregnancy and pregnancy complicated by diabetes. Clin. Sci. 106(1):93-98.

Winkler, K; Wetzka, B; Hoffmann, MM; Friedrich, I; Kinner, M; Baumstark, MW (2003). Triglyceriderich lipoproteins are associated with hypertension in preeclampsia. J. Clin. Endocr. Metab. 88(3):162-166. 